\title{
RESPONSABILIDAD SOCIAL... MISIÓN DE LA UNIVERSIDAD
}

\author{
Social Responsibility... Mission of the University \\ Mg. Susana Alvarado Alfaro ${ }^{1}$
}

\begin{abstract}
${ }^{1}$ Magíster en Educación Mención: Administración y Planificación de la Educación Superior. Profesora Principal de la Facultad de Enfermería, Universidad Nacional San Luis Gonzaga. Ica, Perú.
\end{abstract}

La responsabilidad social que le toca a la Universidad en el presente milenio en un mundo globalizado, que se informa y se comunica a través de las redes sociales, se presenta como un desafío, dado a que no solamente tiene que formar profesionales al más alto nivel, y competitivos, de la mano de la tecnología punta, sino también tiene que realizar grandes esfuerzos para formar profesionales humanísticos(1), sensibles a los problemas sociales, comprometidos con el desarrollo y la inclusión social.

La educación universitaria debe ser el refugio permanente de lo más noble y defendible del hombre, de su derecho a ser persona antes que un profesional solamente ilustrado; ante la incertidumbre y la oscuridad, le corresponde a la universidad ser luz intelectual e iluminar, debe educar en libertad y para la libertad, ser ella misma libre, de esa manera cumple en ser la conciencia crítica de la sociedad y por tanto es elucidante y liberadora.

Uno de los ámbitos de mayor compromiso de la universidad es el de la ciencia (1), de la filosofía en la búsqueda de la luz sobre la verdad y los valores humanos. No aporta luz cuando se muestra apática, neutral, y se dedica exclusivamente a la búsqueda de resultados útiles, considerando a la ciencia sólo como una herramienta sin sello, ni signo, ni valor.

La Universidad debe fomentar la filosofía, en la actualidad constatamos que en el mejor de los casos se le deja subsistir, tal vez porque la verdadera filosofía genera y acrecienta el pensamiento analítico, crítico, la imaginación creadora, la inventiva y la pluralidad. Cuando en una sociedad como la nuestra se padecen de males, que se acrecientan y que van de la mano con la pérdida de valores, principios y ética, la universidad tiene la responsabilidad de pensar, imaginar, construir utopía, de inventar, y de iluminar donde todo parece oscuro, debe tomar todos los datos de la realidad, sin idealismos ni mistificaciones, y someterlos a un análisis muy serio para poder, con autoridad y energía, denunciar los errores y vicios que deben evitarse y plantear con lucidez las soluciones a que hubieran lugar, la negativa a este deber universitario significa traicionar a la misión de la universidad: la verdad y el compromiso social.

Muchas de las universidades consideran que su responsabilidad social termina cuando logran la exigencia y la calidad académica, y forman profesionales para el mercado, este razonamiento nos parece ilegítimo, aunque explicable por quienes lo generan. El poder del conocimiento, el desarrollo de habilidades y destrezas pueden utilizarse y de hecho se utilizan para la afirmación del individualismo, para la acumulación de privilegios y beneficios de grupos, de poder, lejos de propiciar una distribución equitativa o por lo menos inclusiva, notoriamente han acentuado la diferencia de clases y la injusticia social.

Esta formación en la responsabilidad social (2) no puede darse solamente por evidencias racionales, es necesaria la autoridad moral de los educadores y de la misma universidad. ¿Cómo puede hablar la universidad de justicia social, si se confiesa defensora de las clases privilegiadas? ¿Cómo puede hablar con autoridad de libertad, si es un apéndice del poder político?, se requiere pues de una universidad libre y autónoma. 


\section{MISIÓN DE LA UNIVERSIDAD.}

La universidad debe decidir ser fiel a su misión (1), reinventándose, si bien es cierto que los conocimientos del pasado son obsoletos en el presente, también es cierto que los conocimientos del presente pronto serán caducos, entonces parece evidente que es más importante la formación que la información, es decir que la formación debe orientarse más a la afirmación de las destrezas mentales, a la capacidad analítica y crítica, a la habilidad para discernir, juzgar, elegir, en síntesis, a desarrollar la personalidad del educando, para que afronten con lucidez intelectual y calidad humana el futuro cada vez más impredecible.

A la universidad le toca una nueva misión bajo el paradigma de la responsabilidad social, para superar la proyección social y extensión universitaria que son apéndices bien intencionados de su función central de formación estudiantil y producción de conocimientos, y debe asumir la verdadera exigencia de la responsabilidad social, partiendo de una reflexión sobre sí misma en su entorno social, un análisis de su responsabilidad, y sobre todo de su parte de culpabilidad en los problemas crónicos de la sociedad, dejando de pensarse como una burbuja de paz y racionalidad en medio de una tormenta en que se debate una lujosa nave tecno-científica pero sin rumbo (3).

\section{LA RESPONSABILIDAD SOCIAL DE LA UNIVERSIDAD.}

La responsabilidad social universitaria exige desde una visión holística, articular diversas partes de la institución en un proyecto de promoción social de principios éticos y de desarrollo social equitativo y sostenible, para la producción y transmisión de conocimientos responsables y la formación de profesionales responsables (4).

Las orientaciones estratégicas de responsabilización social universitaria se deben enfocar en 4 líneas de acción institucional.

1. Gestión interna. La universidad debe ser una comunidad ejemplar de democracia, equidad, transparencia y modelo de desarrollo sostenible.

2. Docencia. Capacitación en responsabilidad social, y promover el aprendizaje basado en proyectos.

3. Investigación. Promover investigaciones para el desarrollo, y firmar convenios con distritos urbano marginales o rurales.

4. Proyección social. Implementar proyectos de desarrollo que sean fuente de investigación.

"La Universidad debe diseñar un nuevo contrato social con la sociedad"

\section{BIBLIOGRAFÍA.}

1. Gobierno del Perú. Ley Universitaria № 23733. Art. $2^{\circ}$ inc. C. Lima, Perú. 1983.

2. Universidad de Concepción de Chile. Programa de estudios sobre la Responsabilidad Social Universitaria en el marco del Plan Estratégico de la Universidad. Concepción, Chile. 2002.

3. Morin E. El Método 6: La Ética. Cátedra. Madrid, España. 2004.

4. Vallaeys F. Que es la Responsabilidad Social Universitaria. Pontificia Universidad Católica del Perú. Lima, Perú. 2008. 